During the last ten years the fall in the mortality from consumption has been, in Great Britain, I9; Scotland, 24; Ireland, 24; Germany, I8; London, 3o; Berlin, 24; Paris, 3. This period synchronises with that during which the National Assoclation for the Prevention of Consumption has been at work-also with Mr. Burns's term of office at the head of the Local Government Board; but during the same period the drink bill per head of the population in this country has fallen from $4 l$. I2s. to $3 l .6 s .8 d$. In Paris, on the other hand, no such fall has been recorded. Whether this be a cause or a symptom merely, this aspect of the question must receive careful and respectful consideration. Other points were brought forward during the conference, often with sreat force and wealth of argument. One thing which stamped this conference as something out of the common run of such meetings was the fact that enthusiastically as each man spoke of the special branch of the subject on which he was engaged, there was none of the "pushing of wares" to the exclusion of everything else that has sometimes characterised such meetings.

The optimistic note struck by the President of the Local Government Board in his opening address was sounded again and again by later speakers, the most hopeful of whom looked forward to the extermination of tuberculosis from cattle and man alike within the next thirty-five or fifty years, maintaining that this could readily be effected if a proper apportionment of the resources at the command of those who are dealing with the disease can be arranged. The credit of the sanatorium treatment has suffered in certain quarters from the fact that careless advocates have assigned to it functions that it was not fitted to perform, whilst others, opponents, equally careless and uninformed, have not taken into account the educational function of the well-governed and properly directed sanatorium. Alí are agreed, of course, that it is impracticable to submit all tuberculous patients to ordinary sanatorium treatment, and that the dispensary system must be brought into play to assist and supplement the work of the sanatorium. This dispensary system has many earnest advocates, and with certain extensions and linking up with the sanatoria on one hand and the hospital on the other there lie within it great potentialities.

In connection with the section of preventive work the optimistic spirit that manifested itself throughout threw into strong relief the feeling that far more might be done in the provision of open-air shelters, for tuberculous patients attending dispensaries and continuing at work, than has yet been done. Several speakers directed attention to the luxurious sanatoria that have been erected in various parts of the kingdom, where, owing to the enormous initial cost and the great expense of administration, the charges must necessarily be prohibitive except to those well endowed with this world's goods. Are these costly buildings necessary or even desirable? they ask. If tuberculosis is to be eradicated within the next thirty or forty years, to what use can such large and solid buildings be put when they have served their primary purpose? Moreover, would not the process of eradication of tuberculosis go on much more quickly if the money spent on these palatial buildings could be directed to the provision of a large number of open-air shelters, in some cases grouped around more solidly constructed administrative blocks, in others placed at the disposal of the dispensaries for the accommodation of single patients at or near their own homes? These shelters might be very inexpensive, and, in many cases, might be destroyed as soon as they had served their purpose. More substantial and comfortable buildings for the No. 2 I 78 , VOL. 87$]$ reception of patients in the later stages of the disease, where there is little to be hoped for from treatment except alleviation of pain-buildings from which should be dissociated all names and terms likely to depress the patient-may well be provided, even at somewhat substantial outlay, especially as after they have served the purpose for which they are designed they may be con. verted into hospitals for the reception of other classes of patients.

The question of different methods of medication is not one to be discussed at a public conference, and, very judiciously, was not taken up. Some of the speakers, however, referred to the necessity for the continuance of experimental work. Here the prophecies of the President of the Local Government Board should have some weight in determining the nature of the efforts to be made and the character and mode of financing these efforts. It is certainly unnecessary to make provision for permanent endowments for the carrying on of this work. An immediate liberal subsidy will be of far greater value in ensuring the desired results than a large sum set aside of which only the interest can be used.

As in the case of shelters, \&c., the money available should be utilised to cover as much ground as possible and at once. Extensive and immediate treatment, both curative and preventive, and well-devised experiments carried out as promptly and on as large a scale as possible, will do far more to stamp out tuberculosis than will efforts extending over a longer period, and in the long run far more costly.

The National Association for the Prevention of Consumption has been working away quietly and systematically for some time; much of its work in the earlier days of its existence was spadework of a very unobtrusive character, and certain critics, perhaps not very kindly disposed, have from time to time been prone to grumble at what they were pleased to call its inertness. For several years past, however, such criticism has been seen to be very much beside the mark, and the London conference, which was the last of a long series, has supplied ample evidence of the valuable work that has been done by the Association, demonstrating to those most directly concerned "what they shall do to be saved" from the white plague. With the facilities now offered by Mr. Lloyd George for putting into force some of the methods recommended by the conference, with a united effort made in matters on which all are agreed, such a shrewd blow may be struck at tuberculosis as it has not received since Koch made the announcement of his epoch-making discovery--the discovery of the tubercle bacillus.

\section{DR. JOHN BEDDOE, F.R.S.}

$W^{E}$ regret to have to record that Dr. John Beddoe, the distinguished anthropologist, died on July I9 at Bradford-on-Avon.

Dr. Beddoe, who was born at Bewdley in 1826 , was the first to make exact observations on the physical characters of living races over wide areas, and he will always be regarded as the founder of our knowledge of the physical anthropology of the living populations of Europe.

So early as 1846 he began to make observations on hair and eye colours in the West of England, and though he found his first system unsatisfactory and abandoned it, he resumed the work, on the occasion of a visit to Orkney in I 852 , and continued these observations to the end of his active life when- 
ever his travels brought him in contact with new peoples.

Owing to his delicate health in childhood and youth, he was cut off from outdoor games and sports, but made good use of his time indoors by devoting it to a course of wide and solid reading. The effect of this is seen in the numerous and illuminating historical and other allusions in his anthropological books and memoirs.

Abandoning the study of the law, for which he was at first destined, he found a much more congenial study in medicine. He commenced his medical studies at University College, London, and completed them at Edinburgh University, where he took his M.D. in 1853 . He was house physician at the Edinburgh Infirmary for fifteen months under the direction of such distinguished physicians as Christison, Simpson, and Syme.

In 1854 the Crimean War offered him the opportunity of visiting eastern Europe as a member of a civil medical staff sent out by the War Office to supplement the work of the military staff. Here he made good use of spare time to make observations on the Turlss and other Eastern races he came in contact with.

On his return from the Crimea he resolved to spend a winter of study in the Vienna hospitals, and in his journeyings to and from Vienna he collected a great deal of anthropological material in Holland, Germany, Austria, Hungary, and Italy.

In 1867 he was awarded by the Council of the Welsh National Eisteddfod a prize of a hundred guineas for the best essay on the origin of the English nation. His essay was afterwards expanded into his well-known book, "The Races of Britain."

In 1868 Dr. Beddoe was president of the Anthropological at the same time that Huxley was president of the older Ethnological Society. The amalgamation of these two rival societies into a single society, the Anthropological Institute (now the Royal Anthropological Institute), which has done so much to promote the study of anthropology in this country, was due to a great extent to the efforts of Beddoe. $\mathrm{He}$ also took an important part in the movement which led to the constitution of anthropology as an independent section at the British Association.

Dr. Beddoe was president of the Anthropological Institute in 1889 . In 1890 he delivered the Rhind Lectures on "The Anthropological History of Europe," a work which shows his unique knowledge of the physical characters, the migrations, and evolution of the peoples of Europe. In 1905 he delivered the Huxley lecture of the Royal Anthropological Institute, and quite lately he was appointed honorary professor of anthropology in the Bristol University.

When we consider that the large amount of anthropological research done by Beddoe was carried out during the intervals of leisure in a busy professional life, we cannot help being astonished at the amount of very valuable work he has done, nor withhold our admiration for the devotion to science which enabled him to persist in it through so many years. Beddoe was a pioneer in a new line of scientific investigation, and his example has been powerful in stimulating other investigators to carry out similar work. The great survey of the hair and eye colours of the school children of Germany carried out by Virchow was without doubt due to the stimulus of Beddoe's pioneer work, and a great deal of similar work has since been carried out by other investigators. The name of John Beddoe will always occupy an honourable place in the history of anthropology.

$$
\text { NO. } 2178 \text {, VOL. 87] }
$$

\section{DR. H. TIMBRELL BULSTRODE.}

D. H. TIMBRELL. BULSTRODE, who died suddenly from heart failure on July 22 , was one of the senior medical inspectors of the Local Government Board, having been appointed to that office by Mr. Ritchie in 1892 . His death was unexpected and will be widely regretted.

Dr. Bulstrode obtained his medical education at Cambridge University and St. Thomas's Hospital. Since his appointment to the Local Government Board he had, in addition to the more routine work of the medical inspectorate, been engaged under three successive medical officers in work of a more special nature implying exceptional skill in epidemiological investigation. It is in regard to this work that his high reputation was made. Three of his reports to the Local Government Board have been presented to Parliament as command papers. Of the subjects at which he worked, that of the relationship of contaminated shellfish to the prevalence of illness, and especially to enteric fever, is particularly important. Early in the nineties of last century the attention of the Local Government Board was directed to the possible causation of outbreaks of enteric fever, as well as of cholera, by the consumption of contaminated oysters, and Dr. Bulstrode was commissioned to make a comprehensive investigation into the subject. $\mathrm{He}$ visited all the districts in England and Wales in which there were oyster layings, and collected all the known literature on the subject of his inquiry. His report, which was presented to Parliament in 1894, was illustrated by a series of charts which indicated the position of all the principal oyster layings in England and Wales, and the positions of sewers in their neighbourhood. The issue of this report necessarily and properly caused much damage to the trade in oysters as then carried on. Its more permanent effect has been to improve the conditions under which a very large proportion of the total oysters in this country are grown and fattened.

Dr. Bulstrode's next investigated several deaths and a considerable number of cases of enteric fever which occurred after mayoral banquets at Winchester and Southampton, and clearly traced these to the consumption of contaminated oysters. Early in the current year a report by Dr. Bulstrode was presented to Parliament dealing with shellfish other than oysters in relation to disease. This report, which is a comprehensive one, brings up to date epidemiology in association with oysters, and contains a detailed account of the principal shellfish beds of mussels and cockles. The volume, like its predecessor on oysters, is illustrated by a valuable series of charts showing the topography of the beds in relation to sewage pollution. Dr. Bulstrode attended many meetings of the Royal Commission on Sewage Disposal which had the oyster and other shellfish difficulties under consideration.

Another public health question with which Dr. Bulstrode was particularly concerned is that of tuberculosis. In 1903 he gave the Milroy lectures at the Royal College of Physicians, choosing the subject of tuberculosis. In I905 he was associated with Dr. Theodore Williams as a representative of the British Government at the International Congress on Tuberculosis at Paris. In Igo8 Dr. Bulstrode's report on sanatoria for consumption was issued and presented to Parliament. This extremely valuable work on sanatoria in England and Wales was republished by H.M. Stationery Office in a cheaper edition, the demand for it having been large.

Dr. Bulstrode, at the time of his death, was engaged in an inquiry, as a representative of the Local 